\title{
Predicted norovirus resurgence in 2021- 2022 due to the relaxation of nonpharmaceutical interventions associated with COVID-19 restrictions in England: a mathematical modeling study
}

Kathleen M. O'Reilly ${ }^{1 *}$ (D, Frank Sandman ${ }^{1,2,3}$, David Allen ${ }^{4}$, Christopher I. Jarvis ${ }^{1}$, Amy Gimma', Amy Douglas ${ }^{5}$, Lesley Larkin ${ }^{5}$, Kerry L. M. Wong ${ }^{1}$, Marc Baguelin ${ }^{1,6}$, Ralph S. Baric ${ }^{7}$, Lisa C. Lindesmith7, Richard A. Goldstein ${ }^{8}$, Judith Breuer $^{8,9}$ and W. John Edmunds ${ }^{1}$

\begin{abstract}
Background: To reduce the coronavirus disease burden in England, along with many other countries, the government implemented a package of non-pharmaceutical interventions (NPIs) that have also impacted other transmissible infectious diseases such as norovirus. It is unclear what future norovirus disease incidence is likely to look like upon lifting these restrictions.

Methods: Here we use a mathematical model of norovirus fitted to community incidence data in England to project forward expected incidence based on contact surveys that have been collected throughout 2020-2021.

Results: We report that susceptibility to norovirus infection has likely increased between March 2020 and mid-2021. Depending upon assumptions of future contact patterns incidence of norovirus that is similar to pre-pandemic levels or an increase beyond what has been previously reported is likely to occur once restrictions are lifted. Should adult contact patterns return to $80 \%$ of pre-pandemic levels, the incidence of norovirus will be similar to previous years. If contact patterns return to pre-pandemic levels, there is a potential for the expected annual incidence to be up to 2 -fold larger than in a typical year. The age-specific incidence is similar across all ages.
\end{abstract}

Conclusions: Continued national surveillance for endemic diseases such as norovirus will be essential after NPIs are lifted to allow healthcare services to adequately prepare for a potential increase in cases and hospital pressures beyond what is typically experienced.

Keywords: Norovirus, Transmission, Seasonality, Mathematical modelling, Surveillance, COVID-19

\footnotetext{
* Correspondence:

${ }^{1}$ Centre for Mathematical Modelling of Infectious Diseases, Department of Infectious Disease Epidemiology, London School of Hygiene \& Tropical Medicine, London, UK

Full list of author information is available at the end of the article
}

(C) The Author(s). 2021 Open Access This article is licensed under a Creative Commons Attribution 4.0 International License, which permits use, sharing, adaptation, distribution and reproduction in any medium or format, as long as you give appropriate credit to the original author(s) and the source, provide a link to the Creative Commons licence, and indicate if changes were made. The images or other third party material in this article are included in the article's Creative Commons licence, unless indicated otherwise in a credit line to the material. If material is not included in the article's Creative Commons licence and your intended use is not permitted by statutory regulation or exceeds the permitted use, you will need to obtain permission directly from the copyright holder. To view a copy of this licence, visit http://creativecommons.org/licenses/by/4.0/ The Creative Commons Public Domain Dedication waiver (http://creativecommons.org/publicdomain/zero/1.0/) applies to the data made available in this article, unless otherwise stated in a credit line to the data. 


\section{Background}

In late January 2020, COVID-19 was first detected in the United Kingdom (UK) [1], and in response to increasing incidence and hospitalisations, the UK entered the first of three national lockdowns on the 23rd of March 2020. The lockdowns and other social restrictions resulted in a reduction in contact patterns in the community, as shown through self-reported contact rates collected using online surveys [2] and other metrics [3]. Subsequently, reports to national surveillance for many endemic diseases, including norovirus, declined across England throughout the rest of 2020 [4]. This reduction in reports of infectious disease has been consistent across many pathogens and observed in other countries where non-pharmaceutical interventions (NPIs) for the control of COVID-19 have been implemented (e.g. Australia [5, 6] and the USA [7, 8]). With the introduction of vaccination against COVID-19 in England, a considerable reduction in COVID-19 hospitalisations and deaths has been observed and this intervention has superseded the blunt tool of NPIs. The UK roadmap out of lockdown details the gradual relaxation of NPIs in 2021 [9], which will likely result in contact patterns more consistent with those seen prior to 2020 .

Norovirus is an endemic viral infection present globally across high- and low-income countries with-as yet-no commercially available vaccine [10]. Norovirus infection can be asymptomatic or can result in gastrointestinal disease symptoms such as stomach cramps, diarrhoea and vomiting. In more vulnerable groups, such as the elderly or immunocompromised, norovirus can result in more severe and/or prolonged disease, and affected individuals may require hospitalisation for treatment. A recent analysis of hospital data in England ascribes an average of 40,800 (with an interquartile range (IQR) of 40,500-41,400) hospital episodes where norovirus was the primary diagnosis and a further 61,500 (IQR 58,700-62,500) with norovirus as a secondary diagnosis, meaning that norovirus is a significant public health and economic burden in England [11] and during hospital outbreaks can result in ward closures. Norovirus-associated mortality within Europe has been estimated as 0.2 (95\% uncertainty interval $0.1-0.2)$ deaths per 100,000 persons [12], which is at least 100fold less than equivalent estimates for all-cause influenza illness [13]. Norovirus is the most common cause of gastrointestinal infections globally and has the highest burden of disease for intestinal infections in the UK [14]. Infections and outbreaks occur more frequently in the winter months, and in England are monitored through multiple national surveillance systems (e.g. [15]) to ensure that unusual activity is detected and that alerts to local health authorities are made for preventive actions. The probability of symptomatic disease is also influenced by host genetic factors [16], the infectious dose of norovirus [17] and previous exposure to infection. Norovirus genetic diversity is characterised by classifying isolates into genogroups, genotypes and strains (also termed variants) [18]; since 2012, the GII.4 genotype 2012 strain (shortened to 'GII.4/2012') has dominated in reports of symptomatic disease in England and globally. Prior to the GII.4/2012 strain, population strain replacement occurred every few years and was consistent across wide geographies. During these strain replacement events, increased norovirus activity in the first year is typically observed, resulting in increased strain on health services [19]. While each dominant strain is termed dominant because it is isolated from a majority of cases in most settings, there is a considerable genetic diversity of the remaining isolates, and the evolutional impact of this remains unclear. The majority of norovirus infection is considered to occur via community transmission, and consequent changes in community contact patterns will likely influence norovirus transmission. However, norovirus has multiple routes of transmission; for example foodborne transmission is thought to contribute to approximately $16-35 \%$ in the UK, based on microbial risk assessments and detailed case investigations [20].

Here we illustrate through modelling the impact of COVID-19 NPIs used throughout 2020-2021 on the dynamics and incidence of norovirus disease in the community, leading on from a recent report of a reduction in norovirus activity [4]. We provide indicators of surveillance to inform what early warning of a norovirus resurgence may look like.

\section{Methods}

\section{Modelling norovirus infection prior to the COVID-19 pandemic (up until March 2020)}

We built an age-structured susceptible-exposedinfectious-recovered (SEIR)-like model that follows a previously developed model for norovirus, focussing on infections with the GII.4/2012 strain [21] (Fig. 1). We assume a population of 100,000 individuals with an age structure similar to that reported in England, and that $20 \%$ of the population remain resistant to norovirus infection due to the nonsecretor status of human histoblood group antigen carbohydrates [22]. Upon infection, individuals are assumed to enter a short stage of exposure (or pro-dromal infection) and then become fully infectious and symptomatic for on average of 2 days [23, 24] (full details of the model, including differential equations and parameters, are given in 'Additional file 1'). Individuals then enter the asymptomatic stage, where they remain moderately infectious [25] for on average 15 days when compared to the symptomatic stage but have no symptoms of disease [26]. Asymptomatic infection is assumed to correspond with norovirus shedding in stool 


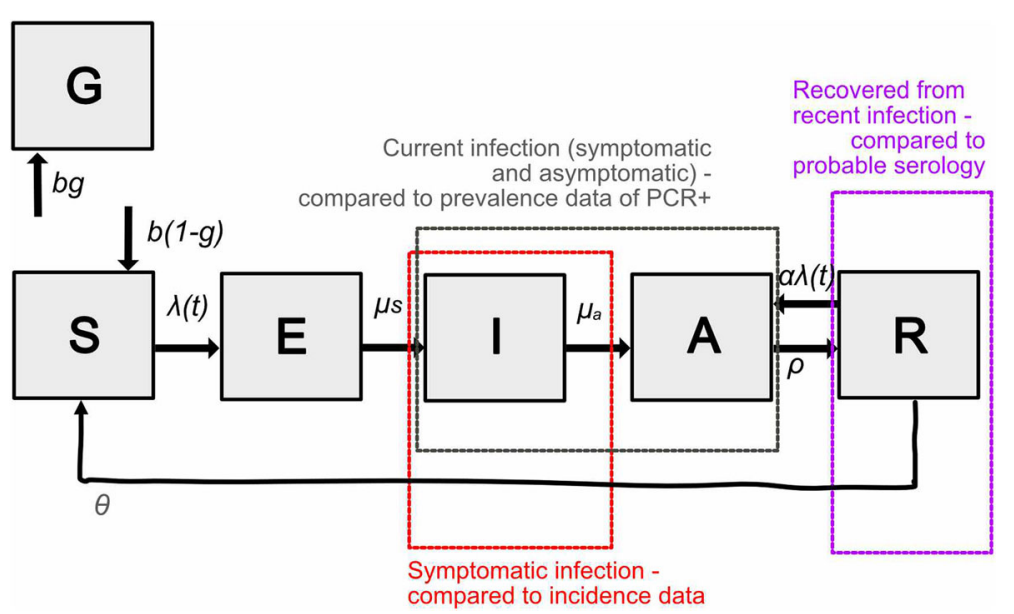

Fig. 1 Schematic of the model for norovirus transmission. Each box represents a compartment of the system of equations; S susceptible, E preinfectious, I infectious and symptomatic, A infectious and asymptomatic, R recovered and $G$ genetically resistant to infection. Dashed boxes illustrate the assumed relationships between the model outputs and available data. The parameters specified in the figure are those used in the main model, see the supplementary information for additional assumptions tested as part of the sensitivity analysis

that can be detected using RT-PCR. Upon recovery, individuals are immune to further symptomatic infection, but can develop an asymptomatic infection. After an average of 5.1 years, individuals are assumed to return to the susceptible class where the infection will be symptomatic again [21]. To capture heterogeneity in transmission between ages, the transmission model is agestructured using eight age groups $(0-4,5-14,15-24$, 25-34, 35-44, 45-54, 55-64, 65+). Symmetric contact rates between and within age groups prior to March 2020 were obtained for England from the European Polymod Study [27] and adapted for the age ranges used in here (using the $R$ package socialmixr). All modelling and analyses were done in the software $R$ (v 4.0.4).

A challenge of norovirus modelling is that there are broad observations in the epidemiology of norovirus which a model should ideally replicate, but these observations are from a wide spectrum of sources, with limitations and biases within each dataset. In the UK, there have been two major studies in recent decades into infectious intestinal diseases (IID), which provide valuable information on community incidence. The first Study of Infectious Intestinal Disease (IID1) in England illustrated that norovirus is a common cause of IID in the community with considerable under-reporting to primary care [23]. A follow-on study (IID2) explored community incidence of gastrointestinal diseases (including norovirus), where incidence was highest in children and declined with age [28], and there was substantial under-reporting within the passive surveillance at the time. Serological data for norovirus is limited (due to challenges in establishing reliable correlates of protection [29] and enzyme immunoassays often being insensitive to strain-specific immunity), but where available, serological responses indicate seroconversion after acute illness [30] and suggest an increasing titre with exposure. In order to capture these general observations while needing to obtain reliable transmission rates within the community, we fit the probability of transmission given a contact to community age-stratified incidence data from IID2 [31] under different assumptions stated above and also include a $20 \%$ under-reporting of symptomatic cases to account for a possible increase in incidence from the GII.4/2012 strain which has dominated symptomatic illness since this time. This one parameter is fitted using a Metropolis-Hastings algorithm, full details of the fitting procedure are provided in 'Additional file 2'. For each scenario, we provide estimates of incidence (i.e. new cases of symptomatic infection) which were compared directly to incidence data. Additional model outputs were provided as a form of validation against what we would expect a realistic model of norovirus to output; estimates asymptomatic prevalence, a proxy for seroprevalence (assumed here to be the proportion of individuals that have recently recovered from symptomatic infection) and estimates of $R_{0}$. Estimates of $R_{0}$ were obtained for the pre-COVID-19 scenarios by running the model to endemic equilibrium and estimating $R_{0}$ assuming $R_{0}=1 / \operatorname{Pr}(\mathrm{S})$. While the fit of the model to the data is the main criteria for model selection, we consider these additional metrics when making decisions on the appropriateness of each set of model assumptions.

While the above model assumptions align well with much of the evidence, there are uncertainties with some assumptions, and alternative assumptions may affect disease dynamics. As part of sensitivity analysis, we additionally include other models which capture the main uncertainties and compare the fit of these models to the 
data and other summary metrics (see 'Additional file 3' for full details).

\section{Modelling norovirus infection during 2020-2021}

From March 23, 2020, onwards, we assume that the agespecific contact rates change as reported in a longitudinal cross-sectional study ('Comix') of in-person contacts in England [32]. Weekly measures of age-specific contact rates were collected from March 24, 2020, and the study will continue to collect additional surveys until September 2021. The weekly contact rates are grouped into nine distinct periods of time including 3 different lockdowns that saw different degrees of NPIs being introduced and restrictions easing again with varying contact rates [33]. The model is first run to endemic equilibrium using pre-pandemic values of age-specific contact rates. Between March 23, 2020, until July 19, 2021, a contact matrix from Comix is used for each period of time (specified in 'Additional file 4'). For later projections, we assume that contact rates return to pre2020 values, an additional scenario that assumes adults only return to $80 \%$ of their pre-pandemic contact rates. We report the expected incidence of symptomatic norovirus infections in time, the proportion of the population susceptible to symptomatic infection. $R_{0}$ was also estimated for each time-period; to do this, we assume that only the contact rates have varied and so use the proportional change in the dominant eigenvalue of contact matrices ( $(9)$ to estimate $R_{0}(\mathrm{t})$, where $R_{0}(t)=R_{o} / \vartheta$.

To support planning and national surveillance, we translate the incidence reported within the model to expected norovirus cases reported to the national Second Generation Surveillance System (SGSS). The SGSS is the national laboratory reporting system which records positive records of causative agents such as norovirus in England from frontline diagnostic laboratories [15]. As norovirus is not a notifiable causative agent in England under the Health Protection (Notification) regulations 2010 [34]. Data were extracted on June 28, 2021, for all specimen types from January 1, 2014, onwards and were deduplicated, providing an estimate of the weekly number of norovirus cases reported to SGSS. From the model, the weekly incidence of symptomatic norovirus per 100,000 was scaled up to national incidence (using Office for National Statistics data on population size for England in 2019 of 56,290,000 individuals). Using the estimates within Tam et al. [14], we assume that for 287.6 (95\% CI 239.1 to 346) symptomatic cases estimated nationally one case is reported within the SGSS. The data were compared to the model and the percentage difference reported, noting that the under-ascertainment reported in Tam et al. is from a laboratory reporting surveillance system in place prior to SGSS meaning that some changes in underascertainment are expected.

\section{Results}

The age-specific incidence of norovirus observed in England is best replicated assuming that primary infection is symptomatic, the duration of asymptomatic infectiousness is 15 to 20 days, and that asymptomatic infection is considerably less infectious than symptomatic infection
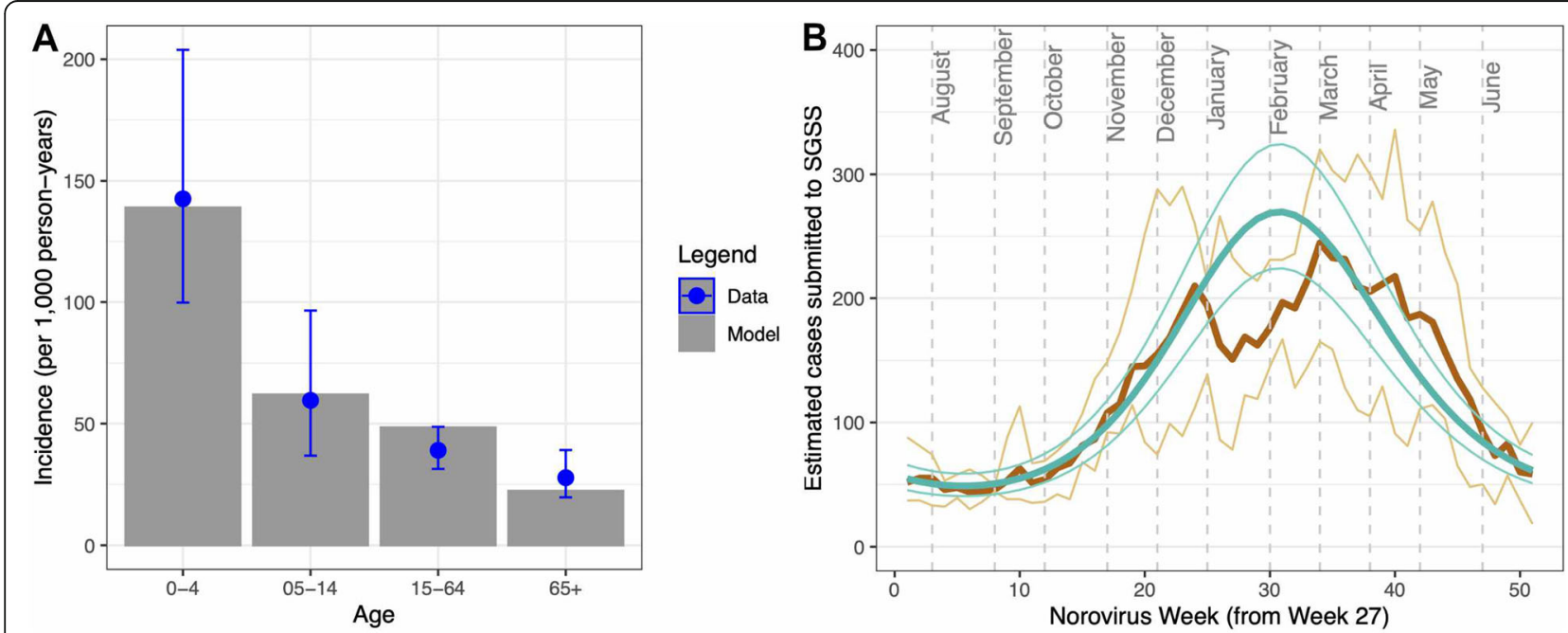

Fig. 2 Comparison of the norovirus model to $\mathbf{A}$ data from Harris et al. of age-specific incidence of symptomatic norovirus infection where this fit was used to estimate the probability of transmission given a contact, $\mathbf{B}$ weekly reported cases of norovirus reported to the SGSS system (thick brown line - 5 year average, thin brown lines_-minimum and maximum). The model incidence (per 100,000 person-years) was extrapolated to a national level, accounting for known under-reporting and under-ascertainment inherent in the surveillance data (287.6 (95\% Cl 239.1-346.0)) and a further $27 \%$ reduction in incidence in the model for alignment with the reported data. Dashed lines indicate the first day of each calendar month. SGSS Second Generation Surveillance System 
(Fig. 2A and Table 1). Simulations that correspond to these observations resulted in a shedding prevalence of less than $1 \%$, the proportion of the population recently recovered from an infection ranging from 24.54 to $30.55 \%$ and an $R_{0}$ between 1.81 and 2.01. The agespecific incidence of symptomatic infection is highest in children aged $<5$ years, and incidence declines with age. When we compare this modelled incidence to the weekly SGSS 5-year average (from norovirus year 2014/
15 to 2018/19), a further $27 \%$ reduction in reporting is needed for cases to be equivalent (Fig. 2B). Other models with different assumptions had a poorer fit to the data and were not taken further in the analysis.

From March 23, 2020, ('lockdown 1') until September 4, 2020, (the 'School reopening' stage), the rate of infection for norovirus is sufficiently low that new infections are rare (Fig. 3A), and an increase in population susceptibility is observed (Fig. 3B). This period corresponds

Table 1 Summary of model assumptions trialled for norovirus, where each model was fitted to age-specific incidence data in England. Models A0-B20 were taken forward to estimate incidence of norovirus between 2020 and 2022

\begin{tabular}{|c|c|c|c|c|c|c|c|c|}
\hline Model & AO & A20 & B0 & B20 & Do & D20 & E0 & Fo \\
\hline \multicolumn{9}{|l|}{ Assumptions } \\
\hline First infection & $\begin{array}{l}\text { Always } \\
\text { symptomatic }\end{array}$ & $\begin{array}{l}\text { Always } \\
\text { symptomatic }\end{array}$ & $\begin{array}{l}\text { Always } \\
\text { symptomatic }\end{array}$ & $\begin{array}{l}\text { Always } \\
\text { symptomatic }\end{array}$ & $\begin{array}{l}50 \% \\
\text { asymptomatic }\end{array}$ & $\begin{array}{l}50 \% \\
\text { asymptomatic }\end{array}$ & $\begin{array}{l}50 \% \\
\text { asymptomatic }\end{array}$ & $\begin{array}{l}\text { Always } \\
\text { symptomatic }\end{array}$ \\
\hline $\begin{array}{l}\text { Duration of } \\
\text { Asymptomatic } \\
\text { infectiousness } \\
\text { (days) }\end{array}$ & 15 & 15 & 20 & 20 & 15 & 15 & 15 & 15 \\
\hline $\begin{array}{l}\text { Asymptomatic } \\
\text { infectiousness } \\
\text { relative to } \\
\text { symptomatic }\end{array}$ & 0.05 & 0.05 & 0.05 & 0.05 & 0.05 & 0.05 & 0.5 & 1 \\
\hline $\begin{array}{l}\text { Under- } \\
\text { reporting } \\
\text { assumed in } \\
\text { fitted data (\%) }\end{array}$ & 0 & 20 & 0 & 20 & 0 & 20 & 0 & 0 \\
\hline \multicolumn{9}{|l|}{ Results } \\
\hline $\begin{array}{l}\text { Probability of } \\
\text { transmission } \\
\text { given a } \\
\text { contact }\left(q_{s}\right)\end{array}$ & 0.1892696 & 0.2070616 & 0.1693301 & 0.1824529 & 0.2183579 & 0.2193598 & 0.374627 & 0.1909186 \\
\hline $\begin{array}{l}\text { Log-likelihood } \\
\text { of age-specific } \\
\text { incidence } \\
\text { when fitted to } \\
\text { data from Eng- } \\
\text { land [15] }\end{array}$ & -77.94 & -190.03 & -72.10 & -107.46 & -667.77 & -850.36 & -1458.08 & -1454.57 \\
\hline $\begin{array}{l}\text { R0 (at endemic } \\
\text { equilibrium) }\end{array}$ & 1.81 & 2.03 & 1.81 & 2.01 & 1.94 & 1.62 & $>10$ & $>10$ \\
\hline $\begin{array}{l}\text { Shedding } \\
\text { prevalence (at } \\
\text { endemic } \\
\text { equilibrium) } \\
(\%)\end{array}$ & 0.18 & 0.25 & 0.303 & 0.41 & 0.718 & 0.70 & 59.44 & 59.77 \\
\hline $\begin{array}{l}\text { Sero- } \\
\text { prevalence (at } \\
\text { endemic } \\
\text { equilibrium) } \\
(\%)\end{array}$ & 24.64 & 30.55 & 24.54 & 29.92 & 27.73 & 37.80 & 20.49 & 20.17 \\
\hline Comments & $\begin{array}{l}\text { Good fit; } \\
\text { used for } \\
2020-2022 \\
\text { projections }\end{array}$ & $\begin{array}{l}\text { Good fit; } \\
\text { used for } \\
2020-2022 \\
\text { projections }\end{array}$ & $\begin{array}{l}\text { Good fit; } \\
\text { used for } \\
2020-2022 \\
\text { projections }\end{array}$ & $\begin{array}{l}\text { Good fit; } \\
\text { used for } \\
2020-2022 \\
\text { projections }\end{array}$ & $\begin{array}{l}\text { Poor fit to } \\
\text { data, } \\
\text { incidence in } \\
\text { younger ages } \\
\text { was under- } \\
\text { estimated and } \\
\text { incidence in } \\
\text { older ages } \\
\text { was over- } \\
\text { estimated }\end{array}$ & $\begin{array}{l}\text { Poor fit to } \\
\text { data, } \\
\text { incidence in } \\
\text { younger ages } \\
\text { was under- } \\
\text { estimated and } \\
\text { incidence in } \\
\text { older ages } \\
\text { was over- } \\
\text { estimated }\end{array}$ & $\begin{array}{l}\text { Poor fit to the } \\
\text { incidence data } \\
\text { (high incidence in } \\
\text { adults) and } \\
\text { unrealistic R0, but } \\
\text { better } \\
\text { comparison with } \\
\text { expected } \\
\text { seroprevalence } \\
\text { and shedding }\end{array}$ & $\begin{array}{l}\text { Poor fit to the } \\
\text { incidence data } \\
\text { (high incidence in } \\
\text { adults) and } \\
\text { unrealistic R0, but } \\
\text { better } \\
\text { comparison with } \\
\text { expected } \\
\text { seroprevalence } \\
\text { and shedding }\end{array}$ \\
\hline
\end{tabular}


with minimal cases reported to the laboratory surveillance SGSS system (Figure S1). This period corresponded with an $R_{0}$ for norovirus ranging from 0.43 to 0.77 , meaning that transmission could not be sustained. The period between September 4, 2020, to January 5, 2021, corresponds to a higher average number of contacts within the population (up to 7.79 in the average number of (unweighted) contacts), an increase of incidence in the model, and outside of the second lockdown and the Christmas period, $R_{0}$ was above 1.00 (see 'Additional file 4'). This increase in incidence was not observed in the SGSS system. The subsequent 'lockdown 3' period corresponds to a reduction in contacts (from 6.61 to 3.47), and the rate of infection falls to low levels again, until schools are re-opened on March 9, 2021 (Fig. 3A). By this time point, the model estimates that the proportion of the population susceptible to symptomatic infection has risen from 54 to $59 \%$ (a 9\% increase) as a result of waning immunity (Fig. 3B, agespecific values given in Additional file 1: Table S1). Subsequently, model scenarios predict a rise in the rate of infection and a resurgence of norovirus in the community resulting in an annual incidence of cases up to 2fold higher than simulations prior to 2020 (Fig. 4A, full details in Additional file 1: Table S1). This time period also corresponds with an $R_{0}$ above 1.00 , where the contact data collected while schools correspond to an estimated $R_{0}$ of 1.28 . However, this prediction is dependent upon assumptions on mixing patterns in the general population; if adult mixing is assumed to be $80 \%$ of preCOVID levels, an increase in incidence is not predicted. Instead, the rate of infection increases but at a lower level, resulting in a gradual increase in susceptibility in the population.
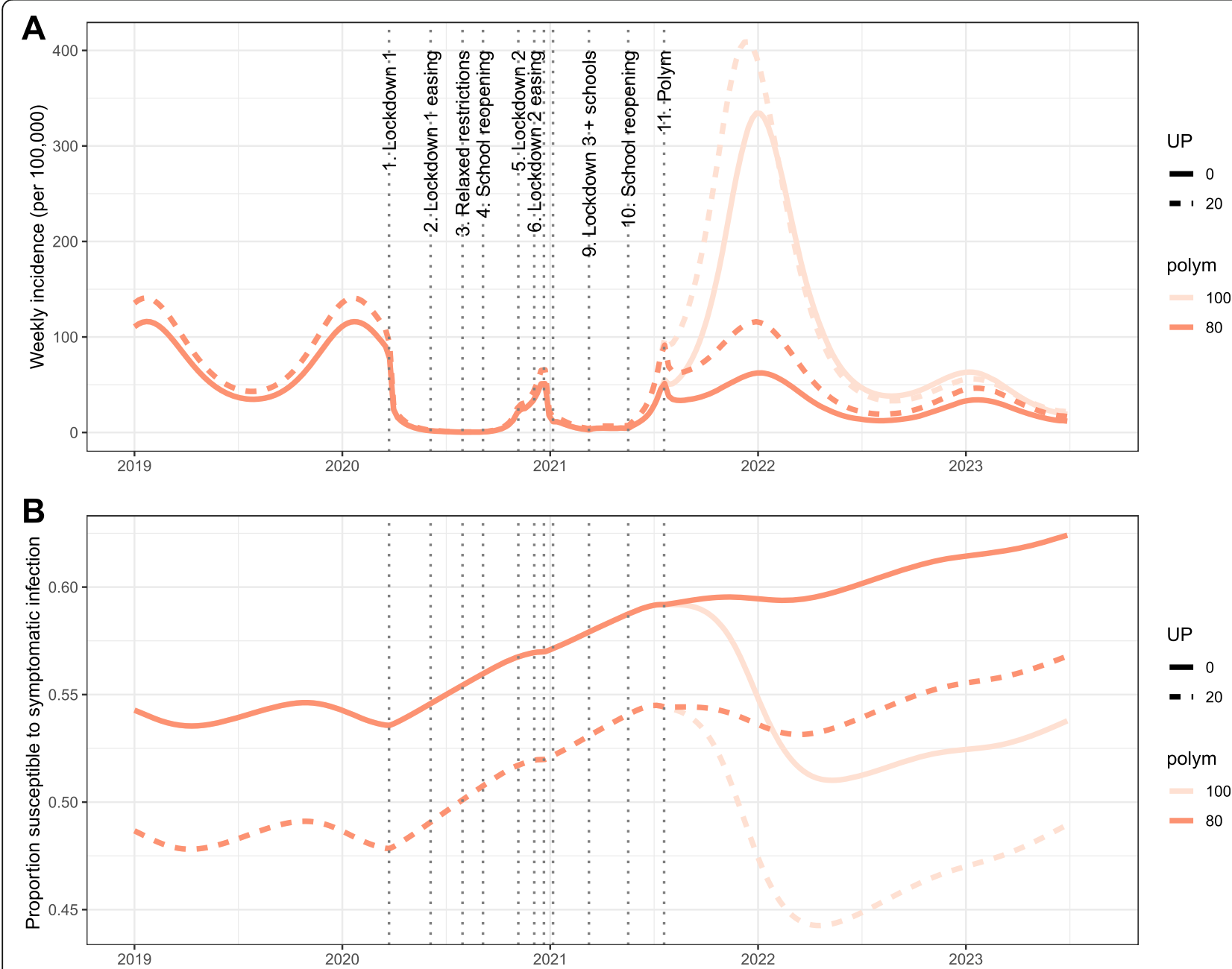

Fig. 3 Estimates of the impact of changing contact patterns due to COVID-19 restrictions on norovirus $\mathbf{A}$ incidence and $\mathbf{B}$ susceptibility to symptomatic infection from January 2019 to June 2023. In each panel, each colour represents simulations that assumptions contact patterns after July 2021 are the same as pre-COVID-19 (light red) or adults have 80\% fewer contacts (red), and allowing for different assumptions about underreporting of norovirus incidence within Harris et al. [31]; solid lines assume no under-reporting and dashed lines assume 20\% underreporting. UP under-reporting, sim simulated duration of asymptomatic infectiousness in days 

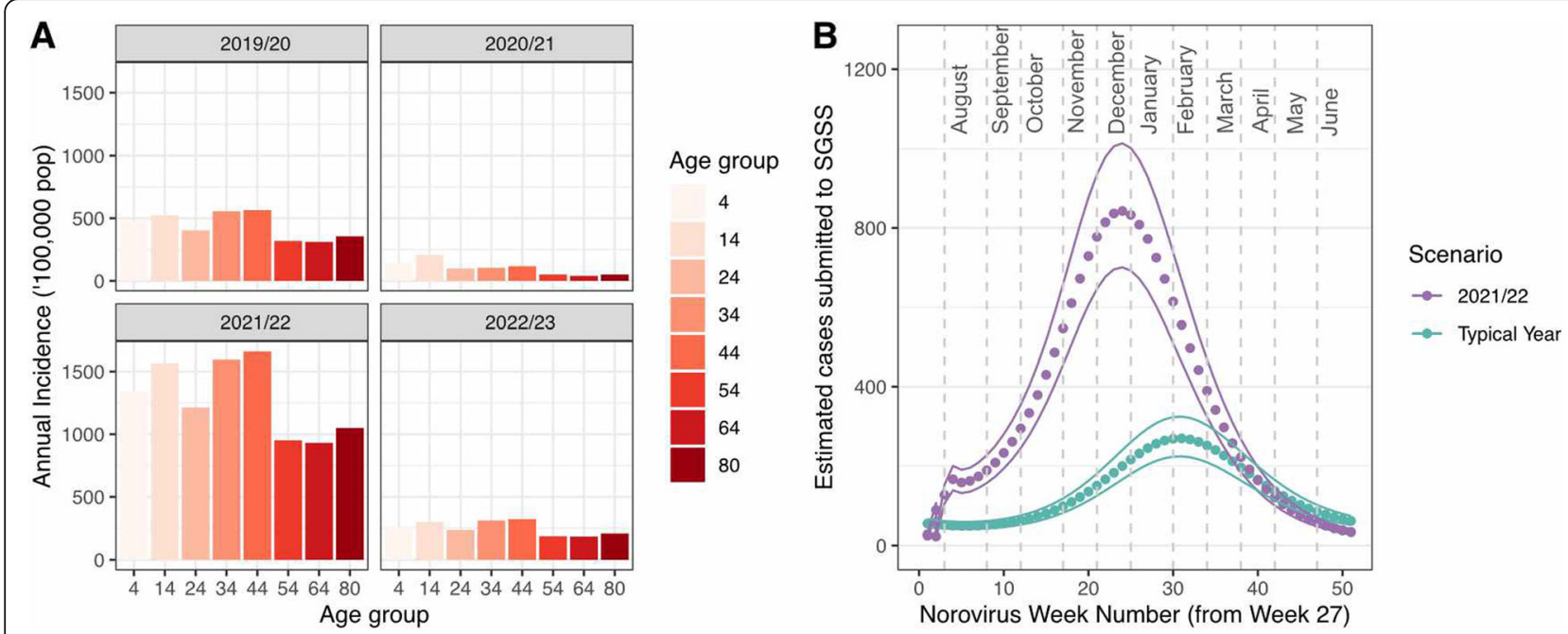

Fig. 4 Model estimates of $\mathbf{A}$ incidence of symptomatic norovirus infections by age and norovirus year, $\mathbf{B}$ predictions of cases reported within SGSS for the 2021/2022 year, compared with a typical norovirus year. Simulations assuming a duration of shedding of 15 days and no underreporting (outcomes from other simulations are shown in 'Additional file 5'). Dashed lines indicate the first day of each calendar month. SGSS Second Generation Surveillance System

We also tested the impact of model assumptions regarding under-reporting and the duration of shedding (Figure S2). Assumptions about under-reporting affect the rate of infection; if incidence was under-reported in Harris [31], this will result in a higher rate of infection in the community and the potential for a more rapid change in incidence. Assumptions on the duration of shedding have a lesser impact; simulation assuming a shorter duration of shedding suggests a higher incidence in the 2021/22 norovirus year (Additional file 1: Table S1).

\section{Discussion}

The reduced reporting of norovirus cases and outbreaks that were observed in 2020 as a consequence of COVID19-associated NPIs has been described within a number of countries, including England [4], Australia [5] and the USA $[7,8]$. Our modelling study quantifies the potential unintended consequences of the build-up of individuals susceptible to norovirus infection in England, with epidemic potential for the autumn/winter of 2021 and 2022. Norovirus is an example of an endemic infectious disease where changes in contact rates can affect both the short and long-term incidence of symptomatic disease. This resurgence is likely to further increase 'winter pressures' within the NHS that may lead to more hospital admissions due to norovirus, hospital outbreaks of norovirus with bed-days lost as beds are kept empty for infection prevention and control, and treatment delays for non-norovirus patients [11, 35]; therefore, preparations for mitigating the effect of an increase in incidence are essential. This is especially true at the current time where there has been considerable disruption to healthcare services due to the COVID-19 pandemic and there are a record number of 5 million people on waiting lists to receive hospital care following the impact of COVID19 in England [36]. While there are several caveats of the modelling to consider in the interpretation of this analysis, this is the first analysis of disease dynamics for norovirus affected by changes in NPIs.

More broadly, the unintended consequences of NPIs are likely to be widespread across other endemic diseases (e.g. respiratory syncytial virus and influenza 37) where incidence pre-COVID-19 was limited by populations being largely immune to infection $[38,39]$. A challenge in the interpretation of the likely future trajectory of incidence is the quantification of how NPIs impact physical contacts in the community and how this impacts the transmission of infectious disease. Here we make use of the longitudinal cross-sectional study of contacts, which has been instrumental in predicting the incidence of COVID-19 [40], and show that these data can be very useful for quantifying dynamics of endemic diseases in addition to COVID-19. Continued collection of these data and incorporation into models of infectious disease will be essential in informing our understanding of disease transmission as the pandemic continues to unfold. It is likely that the impact of NPIs on norovirus, respiratory syncytial virus and influenza was more pronounced than for SARS-CoV-2 because the effective reproduction number $\left(R_{\mathrm{e}}\right.$, equivalent to $R_{0}$ multiplied by the proportion susceptible) for these endemic pathogens is close to 1.00. Theoretically, the NPIs are designed to limit contact rates, which will reduce $R_{0}$ and in turn $R_{\mathrm{e}}$. At least 
in the period of time that has been experienced, this will limit transmission and disease incidence, as we have observed. The impact of further restrictions should still be effective, but with increases in susceptibility, the indirect effect of NPIs on endemic diseases could become less effective with time. Our analyses make the implicit assumption that contacts described within surveys correlate with contacts relevant for infectious disease transmission where the primary mode is direct contact, while this is apparent for infections such as influenza and SARS-CoV-2, there is less evidence for norovirus. These assumptions explain why the rate of infection is predicted to increase when contacts correspond to an $R_{0}$ above 1.00. The reported incidence of norovirus in the coming months, the changing behaviours of the community in contacts and infection prevention, and the actions public health officials will take to prevent a large epidemic, will be the test of this hypothesis. As the COVID-19 pandemic evolves, potentially including more transmissible and vaccine-evading variants, NPIs that include the ongoing working-from-home recommendation through to school closures and lockdowns, remain possible. A major assumption of our model, which reflects the current understanding of norovirus epidemiology, is that contacts with and between children under 5 years are the main driver of norovirus transmission. Consequently, any changes in contact with this age group will have a large effect on norovirus dynamics.

In the analysis, the incidence of norovirus reported was replicated well in the simulations, with the exception of the expected increase in cases at the end of 2020. This potentially suggests that the rate of infection assumed in the model is higher than is experienced in the community, despite the fact that the rate of infection was fitted to community data. Alternatively, the effect of reduced to the SGSS due to changes in healthcareseeking behaviours and reduced laboratory testing of samples obtained may have impacted on the comparator data. This observation means that some caution should be applied to the findings presented here as the model predictions are sensitive to assumptions about contact rates and the probability of transmission, which remain uncertain. Further work will explore this in more detail through the use of additional contact surveys and exploration of other datasets that can improve our understanding of norovirus transmission in the community.

The majority of norovirus disease occurs within the community; there is a significant disease burden resulting in school closures and days of work lost (especially as infection can be experienced relatively frequently) [41]. Hygiene measures, such as handwashing with soap, enhanced environmental cleaning and staying at home when ill, have been part of the usual recommended practice to reduce norovirus transmission, but the
COVID-19 pandemic has indirectly enforced the adherence to these measures. It is possible that beyond 2021, these measures may remain as usual practice in the short to medium term, which may well mean that the incidence of infectious diseases such as norovirus is lowered compared with historical norms. An additional challenge of norovirus largely being a community illness is that norovirus surveillance is affected by both underascertainment and under-reporting, resulting in considerable uncertainty in true estimates of burden. With an increase in community transmission of norovirus, we would expect an increase in incidence, including severe disease in institutional settings (such as care homes for the elderly). However, much of the COVID-19 interventions targeted at institutional settings may also limit the incidence of norovirus; the impact of these interventions on norovirus warrants investigation. While we compared the model output to cases reported into the SGSS, surveillance is biased towards cases within hospitals, which will be a combination of community and hospitalacquired infections. For this reason, we have fitted to data from a community cohort study and used the SGSS data as a validation of the model estimates. The data from IID2 is over 10 years old, and may not fully represent incidence experienced in recent years, due to strain replacement in 2012 and hypothesised higher incidence of infection. Indeed, a recent community cohort study in the Netherlands report an incidence of symptomatic norovirus of 339.4 cases per 1000 person-years [42], which is higher than that reported in the IID2. We aimed to overcome the weaknesses in data by having multiple models with varying assumptions to cover a wide range of plausible present-day scenarios of norovirus dynamics. We identified a difference between model predictions and SGSS of 73\%, which is well within a plausible range.

A further complexity in norovirus epidemiology is the possibility of strain replacement in the coming months or years; the GII.4/2012 strain has been in circulation in England since 2013 and could continue to dominate, but the emergence of other variants also has the potential [43]. The likelihood and how a new variant may impact norovirus dynamics are currently uncertain and are likely to depend on the relative virulence of a new strain and the heterotypic immunity from infection with the GII.4/2012 strain. Further work will include consideration of strain-specific immunity profiles within the community to understand the impact of multi-strain dynamics and the potential impact of vaccination.

\section{Conclusions}

This modelling study suggests that norovirus incidence in the community is likely to remain approximately similar to or substantially increase beyond what has been 
experienced in years prior to 2020. The results are sensitive to future contact patterns in the community, and the adherence to preventive actions, which will affect the probability of transmission. The lower incidence of norovirus reported in surveillance aligns with model assumptions on reduced contact rates from March 2020 to June 2021 and is consistent with an increase in population susceptibility. The short- to long-term impact of this increased susceptibility places populations at risk of norovirus disease, but the scale of the impact remains to be seen. Continued investment to maintain robust national surveillance systems will remain critical to enable measures to limit the impact of these resurgences and provide essential information to public health bodies to support the implementation of preventive actions.

\section{Abbreviations}

IID: Infectious intestinal disease; NPI: Non-pharmaceutical interventions; SEIR: Susceptible-exposed-infectious-recovered; SGSS: Second Generation Surveillance System; UK: United Kingdom

\section{Supplementary Information}

The online version contains supplementary material available at https://doi. org/10.1186/s12916-021-02153-8

Additional file 1: Full description of the mathematical model for norovirus. Table S1. Parameters within the mathematical model for norovirus and sources of values used.

Additional file 2. Description of the model fitting procedure.

Additional file 3.. Alternative model assumptions for norovirus.

Additional file 4.. Details of 'Polymod' and 'Comix' contact matrices.

Additional file 5: Figure S1. Comparison of simulations and cases reported to SGSS between July 2019 to June 2021.

Additional file 6: Figure S2. Investigating the impact of reduced contact patterns from July 2021 compared to pre-pandemic.

\section{Acknowledgements}

The authors are grateful for discussions within the wider Noropatrol consortium. The authors also acknowledge and are grateful for the data obtainable from public health diagnostic laboratories in England that submit laboratory reports of norovirus into SGSS.

\section{Authors' contributions}

$\mathrm{KO}, \mathrm{FS}$, JB and JE conceived the study. $\mathrm{KO}, \mathrm{Cl}, \mathrm{AG}, \mathrm{AD}, \mathrm{LL}$ and $\mathrm{KW}$ carried out data analysis and $\mathrm{KO}$ carried out the modelling. Interpretation of the data findings was done in discussion with $K O, F S, D A, C J, A D, L L, L L, R G, J B$ and $\mathrm{JE}$, and the authors contributed to the final draft of the manuscript and approved the publication.

\section{Funding}

This research was primarily funded by the Wellcome Trust 'Noropatrol' [grant code203268/Z/16/Z]. Additional funding is acknowledged from Public Health England (PHE), which is an executive agency of the Department of Health and Social Care (DHSC), and National Institute for Health, USA (NIAID 1 R01 Al148260). CoMix is funded by the EU Horizon 2020 Research and Innovations Programme - project EpiPose (Epidemic Intelligence to Minimize COVID-19's Public Health, Societal and Economical Impact, No 101003688) and the Medical Research Council (understanding the dynamics and drivers of the COVID-2019 epidemic using real-time outbreak analytics MC PC 19065).

\section{Availability of data and materials}

The code and data used to conduct these analyses are found at https:// github.com/kath-o-reilly/norovirus_NPIs. For data access to the SGSS data used in the study, applicants can apply to the PHE team by emailing noroOBK@phe.gov.uk

\section{Declarations}

Ethics approval and consent to participate

Institutional ethics approval was not sought because this is a retrospective study, and the databases used are anonymised and free of personally identifiable information. Consent was not sought as the data are part of ongoing public health surveillance.

\section{Consent for publication}

Not applicable

\section{Competing interests}

The authors declare that they have no competing interests.

\section{Author details}

${ }^{1}$ Centre for Mathematical Modelling of Infectious Diseases, Department of Infectious Disease Epidemiology, London School of Hygiene \& Tropical Medicine, London, UK. ${ }^{2}$ Statistics, Modelling and Economics Department, National Infection Service, Public Health England, London, UK. ${ }^{3} \mathrm{NIHR}$ Health Protection Research Unit in Modelling and Health Economics, London School of Hygiene and Tropical Medicine, London, UK. ${ }^{4}$ Department of Infection Biology, Faculty of Infectious and Tropical Diseases, London School of Hygiene and Tropical Medicine, London, UK. ${ }^{5}$ Gastrointestinal Pathogens Unit, National Infection Service, Public Health England, London, UK. ${ }^{6} \mathrm{MRC}$ Centre for Global Infectious Disease Analysis, J-IDEA, Department of Infectious Disease Epidemiology, Imperial College London, St Mary's Campus, London, UK. 'Department of Epidemiology, University of North Carolina, Chapel Hill, USA. ${ }^{8}$ Division of Infection and Immunity, University College London, London, UK. 'Department of Microbiology, Virology and Infection Control, Great Ormond Street Hospital for Children, London, UK.

Received: 9 July 2021 Accepted: 4 October 2021

Published online: 09 November 2021

\section{References}

1. Lillie PJ, Samson A, Li A, Adams K, Capstick R, Barlow GD, et al. Novel coronavirus disease (COVID-19): the first two patients in the UK with person to person transmission. J Infect. 2020;80(5):578-606. https://doi.org/10.1016/ j.jinf.2020.02.020

2. Jarvis Cl, Van Zandvoort K, Gimma A, Prem K, Auzenbergs M, O'Reilly K, et al. Quantifying the impact of physical distance measures on the transmission of COVID-19 in the UK. BMC Med. 2020;18(1):124. https://doi.org/10.1186/s12 916-020-01597-8.

3. Gibbs H, Nightingale E, Liu Y, Cheshire J, Danon L, Smeeth L, et al. Detecting behavioural changes in human movement to inform the spatial scale of interventions against COVID-19. preprint. Epidemiology. 2020. https://doi.org/10.1101/2020.10.26.20219550.

4. Douglas A, Sandmann FG, Allen DJ, Celma CC, Beard S, Larkin L. Impact of COVID-19 on national surveillance of norovirus in England and potential risk of increased disease activity in 2021. J Hosp Infect. 2021;112:124-6. https:// doi.org/10.1016/j.jhin.2021.03.006.

5. Bruggink LD, Garcia-Clapes A, Tran T, Druce JD, Thorley BR. Decreased incidence of enterovirus and norovirus infections during the COVID-19 pandemic, Victoria, Australia, 2020. Commun Dis Intell. 2018;2021:45. https:// doi.org/10.33321/cdi.2021.45.5.

6. Foley DA, Yeoh DK, Minney-Smith CA, Martin AC, Mace AO, Sikazwe CT, et al. The interseasonal resurgence of respiratory syncytial virus in Australian children following the reduction of coronavirus disease 2019-related public health measures. Clin Infect Dis. 2021;ciaa1906. https://doi.org/10.1093/cid/ ciaa1906

7. Lennon RP, Griffin C, Miller EL, Dong H, Rabago D, Zgierska AE. Norovirus infections drop $49 \%$ in the United States with strict COVID-19 public health interventions. Acta Med Acad. 2020;49(3):278-80. https://doi.org/10.5644/a ma2006-124.317. 
8. Nachamkin I, Richard-Greenblatt M, Yu M, Bui H. Reduction in sporadic norovirus infections following the start of the COVID-19 pandemic, 20192020, Philadelphia. Infect Dis Ther. 2021;10(3):1793-8. https://doi.org/10.1 007/s40121-021-00473-z.

9. Anon. COVID-19 response - spring 2021 (Summary). GOV.UK. https://www. gov.uk/government/publications/covid-19-response-spring-2021/covid-19response-spring-2021-summary. Accessed 2 July 2021.

10. Esposito S, Principi N. Norovirus vaccine: priorities for future research and development. Front Immunol. 2020;11. https://doi.org/10.3389/fimmu.2020 01383.

11. Sandmann FG, Shallcross L, Adams N, Allen DJ, Coen PG, Jeanes A, et al. Estimating the hospital burden of norovirus-associated gastroenteritis in England and its opportunity costs for nonadmitted patients. Clin Infect Dis. 2018;67(5):693-700. https://doi.org/10.1093/cid/ciy167.

12. Pires SM, Fischer-Walker CL, Lanata CF, Devleesschauwer B, Hall AJ, Kirk MD, et al. Aetiology-specific estimates of the global and regional incidence and mortality of diarrhoeal diseases commonly transmitted through food. PLoS One. 2015;10(12):e0142927. https://doi.org/10.1371/journal.pone.0142927.

13. Nielsen J, Vestergaard LS, Richter L, Schmid D, Bustos N, Asikainen T, et al. European all-cause excess and influenza-attributable mortality in the 2017/ 18 season: should the burden of influenza $B$ be reconsidered? Clin Microbiol Infect. 2019;25(10):1266-76. https://doi.org/10.1016/j.cmi.2019.02. 011.

14. Tam CC, Rodrigues LC, Viviani L, Dodds JP, Evans MR, Hunter PR, et al. Longitudinal study of infectious intestinal disease in the UK (IID2 study): incidence in the community and presenting to general practice. Gut. 2012; 61(1):69-77. https://doi.org/10.1136/gut.2011.238386.

15. PHE. National norovirus and rotavirus bulletin: management information. GOV.UK. https://www.gov.uk/government/statistical-data-sets/nationalnorovirus-and-rotavirus-bulletin-management-information. Accessed 23 Jun 2021.

16. Lindesmith L, Moe C, Marionneau S, Ruvoen N, Jiang X, Lindblad L, et al Human susceptibility and resistance to Norwalk virus infection. Nat Med. 2003;9(5):548-53. https://doi.org/10.1038/nm860.

17. Teunis PFM, Le Guyader FS, Liu P, Ollivier J, Moe CL. Noroviruses are highly infectious but there is strong variation in host susceptibility and virus pathogenicity. Epidemics. 2020;32:100401. https://doi.org/10.1016/j.epidem.2 020.100401.

18. Chhabra P, de Graaf M, Parra Gl, Chan MC, Green K, Martella V, et al. Updated classification of norovirus genogroups and genotypes. J Gen Virol. 2019;100(10):1393-406. https://doi.org/10.1099/jgv.0.001318.

19. Lopman B, Vennema H, Kohli E, Pothier P, Sanchez A, Negredo A, et al. Increase in viral gastroenteritis outbreaks in Europe and epidemic spread of new norovirus variant. Lancet. 2004;363(9410):682-8. https://doi.org/10.101 6/S0140-6736(04)15641-9.

20. FSA research suggests new higher estimates for the role of food in UK illness. Food Standards Agency. https://www.food.gov.uk/news-alerts/news/ fsa-research-suggests-new-higher-estimates-for-the-role-of-food-in-uk-illness. Accessed 23 June 2021.

21. Lopman B, Simmons K, Gambhir M, Vinjé J, Parashar U. Epidemiologic implications of asymptomatic reinfection: a mathematical modeling study of norovirus. Am J Epidemiol. 2014;179(4):507-12. https://doi.org/10.1093/a je/kwt287.

22. Lindesmith LC, Donaldson EF, Lobue AD, Cannon JL, Zheng D-P, Vinje J, et al. Mechanisms of Gll.4 norovirus persistence in human populations. PLos Med. 2008;5(2):269-90. https://doi.org/10.1371/journal.pmed.0050031.

23. Smith AJ, McCARTHY N, Saldana L, Ihekweazu C, McPHEDRAN K, Adak GK, et al. A large foodborne outbreak of norovirus in diners at a restaurant in England between January and February 2009. Epidemiol Infect. 2012;140(9): 1695-701. https://doi.org/10.1017/S0950268811002305

24. Rockx B, De Wit M, Vennema H, Vinjé J, De Bruin E, Van Duynhoven Y, et al. Natural history of human calicivirus infection: a prospective cohort study. Clin Infect Dis. 2002;35(3):246-53. https://doi.org/10.1086/341408.

25. Sukhrie FHA, Teunis P, Vennema H, Copra C, Beersma MFCT, Bogerman J, et al. Nosocomial transmission of norovirus is mainly caused by symptomatic cases. Clin Infect Dis. 2012;54(7):931-7. https://doi.org/10.1093/cid/cir971.

26. Leon JS, Kingsley DH, Montes JS, Richards GP, Lyon GM, Abdulhafid GM, et al. Randomized, double-blinded clinical trial for human norovirus inactivation in oysters by high hydrostatic pressure processing. Appl Environ Microbiol. 2011;77(15):5476-82. https://doi.org/10.1128/AEM.02801-10.
27. Mossong J, Hens N, Jit M, Beutels P, Auranen K, Mikolajczyk R, et al. Social contacts and mixing patterns relevant to the spread of infectious diseases. PLoS Med. 2008;5(3):e74. https://doi.org/10.1371/journal.pmed.0050074.

28. Amar CFL, East CL, Gray J, Iturriza-Gomara M, Maclure EA, McLauchlin J. Detection by PCR of eight groups of enteric pathogens in 4,627 faecal samples: re-examination of the English case-control Infectious Intestinal Disease Study (1993-1996). Eur J Clin Microbiol Infect Dis. 2007;26(5):311-23. https://doi.org/10.1007/s10096-007-0290-8.

29. Ramani S, Estes MK, Atmar RL. Correlates of protection against norovirus infection and disease-where are we now, where do we go? PLoS Pathog. 2016;12(4):e1005334. https://doi.org/10.1371/journal.ppat.1005334.

30. Cannon JL, Lindesmith LC, Donaldson EF, Saxe L, Baric RS, Vinje J. Herd immunity to Gll.4 noroviruses is supported by outbreak patient sera. J Virol. 2009;83:5363-74.

31. Harris JP, Iturriza-Gomara M, O'Brien SJ. Re-assessing the total burden of norovirus circulating in the United Kingdom population. Vaccine. 2017;35(6): 853-5. https://doi.org/10.1016/j.vaccine.2017.01.009.

32. Jarvis Cl, Gimma A, van Zandvoort K, Wong KLM, Abbas K, Villabona-Arenas CJ, et al. The impact of local and national restrictions in response to COVID19 on social contacts in England: a longitudinal natural experiment. BMC Med. 2021;19(1):52. https://doi.org/10.1186/s12916-021-01924-7.

33. Anon. Timeline of UK government coronavirus lockdowns. The Institute for Government. 2021. https://www.instituteforgovernment.org.uk/charts/ukgovernment-coronavirus-lockdowns. Accessed 22 Jun 2021.

34. Gov.uk. The Health Protection (Notification) Regulations 2010. https://www. legislation.gov.uk/uksi/2010/659/contents/made. Accessed 7 Jul 2021.

35. Sandmann FG, Jit M, Robotham JV, Deeny SR. Burden, duration and costs of hospital bed closures due to acute gastroenteritis in England per winter, 2010/11-2015/16. J Hosp Infect. 2017;97(1):79-85. https://doi.org/10.1016/j. jhin.2017.05.015.

36. O'Dowd A. NHS waiting list hits 14 year record high of 4.7 million people. BMJ. 2021;373:n995.

37. PHE. Six major respiratory viruses reported from PHE and NHS laboratories (SGSS) in England and Wales between week 1, 2011 and week 29, 2021 https://www.gov.uk/government/publications/respiratory-virus-circulationengland-and-wales/six-major-respiratory-viruses-reported-from-phe-and-nhslaboratories-sgss-in-england-and-wales-between-week-1-2009-andweek-23-2019. Accessed 26 Aug 2021.

38. Baker RE, Park SW, Yang W, Vecchi GA, Metcalf CJE, Grenfell BT. The impact of COVID-19 nonpharmaceutical interventions on the future dynamics of endemic infections. PNAS. 2020;117(48):30547-53. https://doi.org/10.1073/ pnas.2013182117.

39. Sullivan SG, Carlson S, Cheng AC, Chilver MB, Dwyer DE, Irwin M, et al. Where has all the influenza gone? The impact of COVID-19 on the circulation of influenza and other respiratory viruses, Australia, March to September 2020. Eurosurveillance. 2020;25(47):2001847. https://doi.org/10.2 807/1560-7917.ES.2020.25.47.2001847.

40. Davies NG. Klepac P, Liu Y, Prem K, Jit M, CMMID COVID-19 working group, et al. Age-dependent effects in the transmission and control of COVID-19 epidemics. Nat Med. 2020;26(8):1205-11. https://doi.org/10.1038/s41591-02 0-0962-9.

41. Harris JP, Iturriza-Gomara M, O'Brien SJ. Estimating disability-adjusted life years (DALYs) in community cases of norovirus in England. Viruses-Basel. 2019;11(2):184. https://doi.org/10.3390/v11020184.

42. Quee FA, de Hoog MLA, Schuurman R, Bruijning-Verhagen P. Community burden and transmission of acute gastroenteritis caused by norovirus and rotavirus in the Netherlands (RotaFam): a prospective household-based cohort study. The Lancet Infectious Diseases. 2020;20(5):598-606. https://doi. org/10.1016/S1473-3099(20)30058-X.

43. Chan MC-W, Roy S, Bonifacio J, Zhang L-Y, Chhabra P, Chan JCM, et al. Detection of norovirus variant Gll.4 Hong Kong in Asia and Europe, 20172019. Emerg Infect Dis. 2021;27(1):289-93. https://doi.org/10.3201/eid2701.2 03351.

\section{Publisher's Note}

Springer Nature remains neutral with regard to jurisdictional claims in published maps and institutional affiliations. 